\title{
Physiological and Perceptual Responses to Self-Selected Exercise Pace on a Track Versus Treadmill
}

Riley Galloway, Ph.D¹, Robert Booker, M.S², Hunter Haynes, M.S ${ }^{1}$, Megan Holmes, Ph.D² and Jacob Gdovin, Ph.D ${ }^{3}$.

${ }^{1}$ School of Kinesiology and Nutrition, The University of Southern Mississippi, Hattiesburg, Missippi, USA, ${ }^{2}$ Department of Kinesiology, Mississippi State University, Starkville, Mississippi State, USA, ${ }^{3}$ Dept. of Physical Education, Sport, and Human Performance, Winthrop University, Rock Hill, South Carolina, USA.

\section{ABSTRACT}

Objective: To investigate physiological and perceptual differences between a controlled and non-controlled exercise modality when walking and running at self-selected pace. Methods: Male and female participants $(\mathrm{N}=30,21.07 \pm 0.88$ years of age) engaged in a familiarization then three test sessions consisting of $\mathrm{VO}_{2}$ max, one-mile walk and run on an indoor track, and one-mile walk and run on a laboratory treadmill. Physiological variables (HR, RER, \& EE) along with perceptual responses (RPE) were obtained during exercise. Exercise intensity (\% $\mathrm{VO}_{2}$ max) was determined for each exercise bout. With a significance level set at $p<0.05$, the following results were found. Results: Walking and running heart rate and rating of perceived exertion were significantly higher on the treadmill compared to the track $(p<0.05)$. However, energy expenditure showed no significant difference between exercise modality $(p=0.611)$. Treadmill exercise resulted in higher $\mathrm{VO}_{2}$ values for males during both walk and run pace $(p=0.041$ and $p=0.002$, respectively). Conclusions: We observed an increased perceived effort during treadmill exercise while maintaining similar energy expenditure. The provisions of autonomy and individuality may decrease perceived effort while maintaining energy expenditure, thus providing positive affective responses promoting adherence. With these differences between modalities in mind, exercise professionals should consider individuality to apply appropriate adjustments to intensity when targeting specific adaptations. These adjustments may also influence adherence to a prescribed program.

Keywords: affective responses, modality, rate of perceived exertion, oxygen consumption

\section{INTRODUCTION}

Increasing engagement in physical activity has become progressively imperative over recent decades due to its beneficial influence on health outcomes, such as increased cardiovascular health, bone mass, improved cholesterol and stroke risk, hypertension, and depression (Hall et al., 2012). Despite these well-acknowledged benefits, adherence to regular exercise regimens remains an obstacle for several reasons including intensity misinterpretation (Browning et al., 2006) and differing physiological and perceptual responses due to modality and environment (Dasilva et al., 2011). For instance, the American College of Sports Medicine (ACSM) recommends 150 minutes per week (30 minutes per day) of moderate-intensity physical activity, or 75 minutes per week of vigorous-intensity, or a comparable combination of the two (Manson et al., 2002). Also, the National Strength and Conditioning Association (NSCA) provides recommendations such as long slow distance aerobic training 1-2 days/week for 30-120 minutes at an intensity of 70\% VO2max (Reuter \& Dawes, 2016). Exercise prescriptions using intensity can be misunderstood and individuals, athletes, and coaches may overestimate intensity, thereby creating a barrier to initiation and adherence. 
People are often introduced to exercise through prescriptive regimens involving strength and conditional professionals and a performance team. These individuals account for various components when designing (i.e. biomechanical, physiological, and perceptual differences) training programs to reduce the likelihood of injury and improve performance. When designing these programs, comfort and enjoyment are paramount for adherence and these are greatly improved with self-selected modalities to avoid intensity misinterpretation (Ceci \& Hassmen, 1991; Emerenziani et al., 2013). A potential moderator of intensity misinterpretation is the incorporation of self-selected and self-regulated walking and running paces. Self-selected can be seen as the pace initially desired while selfregulated includes the minor adjustments to pace during the exercise. How well an individual can reach an intensity while maintaining a positive affective valence (e.g. perception) of the exercise (Amorim et al., 2009; Devi et al., 2014; Ekkekakis \& Lind, 2006) is mitigated by the self-selecting and self-regulating pace decision processes (Browning et al., 2006). Self-selection of exercise intensity has been shown to lower parameters of perceived physical exertion, which enhances the motivation for individuals' adherence (Barnett et al., 2015; Emerenziani et al., 2013). This lower perception of effort during exercise can be considered akin to a positive affective valence which relates to increased future exercise engagement; whereas retrospective affect following exercise does not correlate well with future behavior (Barnett et al., 2015). The relationship between rating of perceived exertion (RPE) and affective valence can be made due to a lower RPE indicating less strenuous and more comfortable exercise which are aspects accounted for in affective responses. Self-selected pace may also eliminate participant confusion of expressing intensity in one of the conventional methods (e.g. percentage of $\mathrm{VO}_{2} \max$, heart rate reserve, etc.).

Recent literature has reported traditional graded testing may overestimate the functional capacity of an individual (Astorino et al., 2000) causing subsequent use of $\mathrm{VO}_{2} \max$ to formulate exercise prescriptions at an exceedingly vigorous intensity (Ekkekakis et al., 2011; Pfeiffer et al., 2002). Less pleasurable experiences are often reported when exercising at excessively high intensity levels (Barnett et al., 2015). However, self-selected pace has been shown to induce a workload equivalent to a lower percentage of $\mathrm{VO}_{2}$ peak and lower RPE, eliciting a positive change in affective valence (Hall et al., 2004). Likewise, overweight and obese individuals express higher RPE scores with increased exercise intensity and show intolerance to increases in intensity compared to normal weight participants (Donnelly et al., 2009). Meanwhile, overweight individuals who are able to walk continually for one hour at a self-selected pace can expect to cover approximately three miles, meeting the daily recommended guidelines from ACSM for walking (Levinger et al., 2004; Morris et al., 2014). Morris et al. (2014) concluded if individuals can begin exercise at light-intensity and continue at selfselected pace, they could perform the necessary amount of exercise to achieve health benefits, while minimizing risk for injury or overexertion.

Exercise modality and setting preference may dictate how and where individuals exercise. However, discrepancies in both physiological and perceptual responses have been observed across various modalities of exercise. Treadmill walking and running has become increasingly popular and provides a convenient method of exercise for many populations (Mooses et al., 2015). Walking is considered a lifestyle form of physical activity when incorporated into activities of daily living. Further, walking is a popular and convenient method of weight management and cardiovascular disease risk reduction while maintaining a positive affective response (Brand \& Ekkekakis, 2018; Levinger et al., 2004; Loftin et al., 2010). Due to differences in environmental setting between treadmill and aboveground walking, concerns arise about which modality provides optimal benefit for varying populations. Research has shown differences between treadmill and above-ground walking on a track in $\mathrm{VO}_{2}$, heart rate (HR), and RPE (Dasilva et al., 2011) suggesting treadmill-based exercise may require an increased amount of effort, in turn increasing perception of effort. However, conflicting results have been found for physiological responses rendering dissemination of information difficult (Dasilva et al., 2011). The present study adds to the information of Dasilva et al. (2011) by including energy expenditure (EE) and also incorporating a one-mile run session.

It has been stated the lack of propelling and supporting one's body mass while running on the treadmill decreases the energy utilized during exercise (American College of Sports Medicine, 2017; DaSilva et al., 2009). However, research shows the addition of a $1 \%$ grade to the treadmill closely reflects the movement pattern, muscle engagement, and propulsion requirement during above-ground jogging (Hall et al., 2012; Inoue et al., 2017). By calculating self-selected speed on the track and on 
the treadmill, accurate comparisons can be made of responses between modalities. Similar conclusions have been formed stating that running on a treadmill results in lack of air resistance which, lowers the energetic cost of the activity (Dasilva et al., 2011; Mooses et al., 2015). Furthermore, research has shown energetic cost remained higher on the track while using a wind screen as compared to treadmill (Pugh, 1970). This may suggest that individuals willingly select a speed on the treadmill that is lower than their actual free environment speed, a possible explanation to the higher values observed on the track as compared to treadmill. Further investigation of alternate exercise modalities is needed to determine differing physiological and perceptual responses to provide insight into exercise prescription and individualization. Therefore, the purpose of this study was to determine the physiological and perceptual responses during a one mile walk and one mile run at self-selected pace between controlled (treadmill, $1 \%$ incline) and non-controlled (track) modalities. It was hypothesized that the treadmill would induce a greater perception of effort and exercise at higher intensity $\left(\% \mathrm{VO}_{2}\right)$, leading to negative affective valence, while other physiological parameters between modality would be similar.

\section{METHODS}

\section{Experimental Approach}

To investigate different acute responses between exercise modalities at self-selected walk and run paces, participants $(\mathrm{N}=30)$ attended multiple sessions where physiological and perceptual variables along with exercise intensity were obtained. Following anthropometric and baseline measures, participants engaged in $\mathrm{VO}_{2}$ max testing prior to the two exercise sessions. For the exercise sessions, all included participants were required to complete a one-mile walk and run on both an indoor track and also indoor treadmill. These methods provided insight to the discrepancies of responses to exercise in differing settings.

\section{Participants}

All participants signed informed consent and procedures were approved by the University Institutional Review Board. Recreationally trained individuals $(\mathrm{N}=30,15$ males, $21.07 \pm 1.53$ years and 15 females, $21.07 \pm 0.88$ years), participated in the present investigation of exercise modality and intensity. Males were significantly heavier and taller
$(85.56 \pm 14.42 \mathrm{~kg}$ and $180.47 \pm 7.76 \mathrm{~cm})$ compared to females $(61.16 \pm 9.84 \mathrm{~kg}, \mathrm{p}<0.001$ and $162.64 \pm 6.04$ $\mathrm{cm}, \mathrm{p}<0.001$, respectively). Mean BMI was calculated and used to classify weight status according to ACSM classifications (American College of Sports Medicine, 2017), for men and women (26.17 \pm 3.52 and $23.14 \pm 3.75 \mathrm{~kg} / \mathrm{m} 2$, respectively). Participant characteristics are outlined in Table 1. The criteria for recreationally trained was determined as participation in a minimum of three hours per week of aerobic activity for the previous three months. Due to recreationally trained status, participants confirmed they were accustomed to the use of an electric treadmill. Participants were excluded if any history of lower body musculoskeletal or central nervous systems limitations relating to posture and motor control within the previous year was identified through the Physical Activity Readiness Questionnaire (PAR-Q). Participants were required to participate in four sessions, each at the same time of day, separated by a minimum of 72 hours to provide adequate recovery time. Prior to each session, participants were instructed to avoid any strenuous physical activity during the 72-hour rest period and refrain from alcohol intake 48 hours prior to each session.

\section{Procedures}

Participants attended multiple sessions to obtain a $\mathrm{VO}_{2}$ max value, physiological responses (HR, RER, $\mathrm{EE})$, perceptual responses (RPE), and exercise intensity ( $\left.\% \mathrm{VO}_{2} \max \right)$. $\mathrm{VO}_{2}$ max tests were conducted on a Trackmaster treadmill (Full Vision, Fulton, KS) using a portable metabolic system (Cosmed K4b2, Rome, Italy). Physiological variables were collected using the same portable metabolic system and Polar heart rate monitor (Polar Electro, Polar FT1, Kempele, Finland) for both indoor track and treadmill sessions. These methods provided insight to the discrepancies of responses to exercise in differing settings.

Session 1: During the familiarization phase, participants signed the university approved consent forms, had anthropometric data measured, and were introduced to the procedural methodology (Borg's 6-20 RPE and $\mathrm{VO}_{2}$ max testing protocol) and all equipment used in the study in an effort to minimize participant discomfort and anxiety.

Session 2: Participants returned to the laboratory and underwent $\mathrm{VO}_{2}$ max testing. There was no mandatory recovery period between sessions 1 and 2 since because the familiarization meeting did not involve 
any strenuous activity. $\mathrm{VO}_{2}$ max tests were conducted on the treadmill and used the portable metabolic system. Testing procedures followed a standard Bruce protocol and continued until the participant reached volitional fatigue or criteria for attainment of $\mathrm{VO}_{2}$ max was achieved (Antoniewicz \& Brand, 2016). Percentage of $\mathrm{VO}_{2}$ max each participant exercised at during each subsequent session was derived from the VO2max value obtained during this session.

Session 3: Following the mandatory 72-hour rest, participants reported to the laboratory before moving to the indoor track. Ambient temperature, barometric pressure, and humidity were recorded via electronic monitoring device (Davis, Vantage Vue, Hayward, CA) to calibrate the portable metabolic system. These environmental factors remained relatively constant for all testing sessions. Participants were fitted to the Cosmed K4b2 unit and Polar heart rate monitor and allowed five minutes of rest to ensure all pieces of equipment were correctly positioned, fully operational, and resting values were obtained. A designated starting position on the track was established and testing commenced once the participant reached this starting mark. Testing consisted of a one-mile walk and one-mile run at a self-selected pace. RPE was collected from the participant for each lap (400-meter) around the track. $\mathrm{HR}, \mathrm{VO}_{2}, \mathrm{EE}$, and respiratory exchange ratio (RER) were continuously collected by the portable metabolic unit throughout the tests. Once the onemile walk was completed, participants rested until physiological parameters (HR, RR, etc.) returned to pre-exercise resting values. Following the rest period, participants completed a one-mile run at self-selected pace. The calculated speed of these miles was used to determine the paces (mph) for the treadmill testing in Session 4. Following completion of the one-mile run, a one-lap self-selected pace walk was implemented as a cool-down.

Session 4: Following another 72-hour rest period, participants returned to the laboratory and followed a similar protocol to Session 3 beginning with a warmup of a 400-meter walk on the laboratory treadmill at the self-selected pace equivalent to that determined from Session 3. Following the warm-up, exercise commenced at the intensity (mph) equivalent to the self-selected pace from Session 3 and participants were instructed to walk one mile. RPE was collected at the time interval equivalent to each lap on the track in Session 3 while the portable unit continuously collected all other parameters. Upon completion of the one-mile walk, a rest period was implemented to allow physiological parameters to return to resting levels. When resting values were achieved, a onemile run began at the self-selected pace determined from Session 3. All exercise prior to cool-down was conducted with a $1 \%$ incline on the treadmill which has been established in previous research to closely match the physiological requirements of walking and running in a free environment with air resistance (Hall et al., 2012). Following completion of the onemile run, a voluntary cool-down was implemented consisting of a walk at self-selected pace.

\section{Statistical Analysis}

All data was exported from the portable metabolic unit into an Excel file. Data were organized by variable and reported as mean \pm standard deviation. Independent t-tests were implemented to determine sex differences in anthropometric characteristics and self-selected walking speed. To investigate the aims of this study, a 2x2 Repeated Measures ANOVA was used to determine differences in physiological and perceptual measures between exercise modality and sex. Bonferroni post-hoc was used to evaluate simple effects and Pearson correlations were evaluated for the relationship between HR and RPE for each modality. All statistical analyses were conducted using SPSS software (Version 22, SPSS, Inc., Chicago, IL). Statistical significance was defined as a $\mathrm{p} \leq 0.05$.

\section{RESULTS}

Thirty recreationally trained individuals met inclusion criteria and participated in the study. Significant differences were found between $\mathrm{VO}_{2}$ max of males and females $(42.40 \pm 5.79 \mathrm{ml} / \mathrm{kg} / \mathrm{min}$ and $35.31 \pm 8.85$ $\mathrm{ml} / \mathrm{kg} / \mathrm{min}$, respectively; $\mathrm{p}=0.026$ ), while the average VO2max of both groups was classified as poor to fair according to ACSM classifications (American College of Sports Medicine, 2017). Participants exercised at approximately $90.6 \%$ of $\mathrm{VO}_{2}$ max when running on the treadmill and $84.9 \%$ of $\mathrm{VO}_{2} \max$ when running on the track.

Although men chose a faster running speed than women $(p=0.018)$, overall self-selected walking and running speeds did not differ between treadmill and track settings, as intended (Table 2.). Men and women's walking and running heart rate $(p<0.001$ and $p=0.012$, respectively) and average RPE $(p=0.001$ and $p=0.001$ ) were significantly higher for treadmill tests compared to track tests (Table 3). Conversely, respiratory exchange ratio was significantly higher during walking and running track tests compared to 
treadmill tests ( $p<0.001$ and $p=0.024$, respectively). Even though physiological parameters such as $\mathrm{HR}$ and RER differed between track and treadmill modalities, no significant differences in EE were indicated between walking or running at selfselected pace on the track or treadmill $(p=0.611$ and $p=0.426$, respectively).

Significant interaction effects between sex and exercise modality were found for walking and running at a self-selected pace for males only. During self-selected walking, the treadmill produced a significantly higher $\mathrm{VO}_{2}, 18.32 \pm 3.35 \mathrm{ml} / \mathrm{kg} / \mathrm{min}$, as compared to the track of $16.69 \pm 2.71 \mathrm{ml} / \mathrm{kg} / \mathrm{min}$ $(p=0.041)$. During running tests, males' $\mathrm{VO}_{2}$ was significantly higher on the treadmill compared to the track $(p=0.002)$. A significant moderate correlation

was also found between RPE and HR on the treadmill $(r=0.426 ; p=0.019)$ and on the track $(r=0.408$; $p=0.025)$.

For both track and treadmill exercise, walking HR was significantly higher for females compared to males ( $p=0.003$ and $p<0.001$, respectively). Males obtained higher values for all other significant differences between sexes. $\mathrm{VO}_{2}$ while walking on the track was significantly higher $(p=0.034)$ as well as treadmill running $(p=0.001)$. EE was significantly higher for males in all conditions of self-selected pace; track walk $(p=0.009)$, track run $(p<0.001)$, treadmill walk $(p<0.001)$, and treadmill run $(p<0.001)$.

\section{DISCUSSION}

Table 1. Participant Characteristics

\begin{tabular}{|c|c|c|}
\hline & Males $(n=15)$ & Females $(n=15)$ \\
\hline Age (years) & $21.07 \pm 1.53$ & $21.07 \pm 0.88$ \\
\hline Height $(\mathrm{cm})$ & $180.47 \pm 7.76^{\star}$ & $162.64 \pm 6.04$ \\
\hline Weight (kg) & $85.56 \pm 14.42^{\star}$ & $61.16 \pm 9.84$ \\
\hline BMI (kg/m2) & $26.17 \pm 3.52^{*}$ & $23.14 \pm 3.75$ \\
\hline SBP $(\mathrm{mm} \mathrm{Hg})$ & $135.63 \pm 14.69^{\star}$ & $117 \pm 7.87$ \\
\hline $\mathrm{DBP}(\mathrm{mm} \mathrm{Hg})$ & $77.30 \pm 12.23$ & $72.80 \pm 6.11$ \\
\hline HR rest (bpm) & $70.7 \pm 7.4$ & $77.6 \pm 7.5^{\star}$ \\
\hline Walk speed (mph) & $3.52 \pm 0.40$ & $3.70 \pm 0.36$ \\
\hline Run speed (mph) & $7.30 \pm 0.91^{*}$ & $6.27 \pm 1.28$ \\
\hline VO $\max (\mathrm{ml} / \mathrm{kg} / \mathrm{min})$ & $42.40 \pm 5.79^{\star}$ & $35.32 \pm 10.10$ \\
\hline
\end{tabular}

$\mathrm{BMI}=$ Body mass index, SBP = Systolic blood pressure, DBP = Diastolic

blood pressure

* Significant differences between sexes $\mathrm{p} \leq 0.05$

Table 2. Physiological and perceptual variables - all participants

\begin{tabular}{|c|c|c|c|c|}
\hline \multirow[b]{2}{*}{ Variable } & \multicolumn{2}{|c|}{ Walk } & \multicolumn{2}{|c|}{ Run } \\
\hline & Track & Treadmill & Track & Treadmill \\
\hline Speed (mph) & $3.61 \pm 0.39$ & $3.61 \pm 0.39$ & $6.78 \pm 1.21$ & $6.78 \pm 1.21$ \\
\hline HR (bpm) & $106.2 \pm 19.8$ & $126.1 \pm 18.3^{*}$ & $174.5 \pm 12.2$ & $182.3 \pm 10.9^{\star}$ \\
\hline RER & $0.90 \pm 0.07^{\star}$ & $0.84 \pm 0.03$ & $1.00 \pm 0.08^{*}$ & $0.96 \pm 0.06$ \\
\hline Average RPE & $6.97 \pm 1.30$ & $8.63 \pm 2.19^{*}$ & $13.67 \pm 2.58$ & $16.37 \pm 3.16^{\star}$ \\
\hline EE (kcal/min) & $5.38 \pm 1.28$ & $5.55 \pm 1.29$ & $11.73 \pm 3.64$ & $12.53 \pm 4.06$ \\
\hline$\% \mathrm{VO}_{2}(\mathrm{ml} / \mathrm{kg} / \mathrm{min})$ & $17.51 \pm 2.84$ & $18.65 \pm 2.90$ & $36.16 \pm 5.37$ & $38.09 \pm 6.10$ \\
\hline
\end{tabular}

$\mathrm{HR}=$ Heart rate, RER = Respiratory exchange ratio, RPE = Rating of perceived exertion, EE = Energy expenditure,

$\% \mathrm{VO}_{2}=$ Percentage of $\mathrm{VO}_{2}$ max during exercise

* Significant differences between modalities within sex, $\mathrm{p} \leq 0.05$

† Significant differences between sexes within modality, $\mathrm{p} \leq 0.05$ 
Table 3. Physiological and perceptual variables - sex differences

\begin{tabular}{|c|c|c|c|c|}
\hline & \multicolumn{2}{|c|}{ MALE } & \multicolumn{2}{|c|}{ FEMALE } \\
\hline Walk & Track & Treadmill & Track & Treadmill \\
\hline Speed (mph) & $3.52 \pm 0.40$ & $3.52 \pm 0.40$ & $3.70 \pm 0.36$ & $3.70 \pm 0.36$ \\
\hline HR (bpm) & $96.0 \pm 18.5$ & $114.5 \pm 16.7^{*}$ & $116.4 \pm 15.7 \dagger$ & $137.0 \pm 11.1 \dagger^{\star}$ \\
\hline RER & $0.90 \pm 0.07^{\star}$ & $0.84 \pm 0.03$ & $0.89 \pm 0.08^{\star}$ & $0.83 \pm 0.04$ \\
\hline Average RPE & $7.27 \pm 1.58$ & $8.27 \pm 1.94^{*}$ & $6.67 \pm 0.89$ & $9.00 \pm 2.42^{*}$ \\
\hline EE (kcal/min) & $5.98 \pm 1.44 \dagger$ & $6.32 \pm 1.13^{\star} \dagger$ & $4.79 \pm 0.75^{\star}$ & $4.78 \pm 0.96$ \\
\hline$\% \mathrm{VO}_{2}(\mathrm{ml} / \mathrm{kg} / \mathrm{min})$ & $16.69 \pm 2.71$ & $18.32 \pm 3.35^{\star}$ & $18.33 \pm 2.81$ & $18.97 \pm 2.44^{*}$ \\
\hline \multicolumn{5}{|l|}{ Run } \\
\hline Speed (mph) & $7.30 \pm 0.91 \dagger$ & $7.30 \pm 0.91 \dagger$ & $6.27 \pm 1.28$ & $6.27 \pm 1.28$ \\
\hline HR (bpm) & $175.1 \pm 12.1$ & $180.3 \pm 12.7^{\star}$ & $173.9 \pm 12.8$ & $184.2 \pm 8.7^{\star}$ \\
\hline RER & $1.03 \pm 0.07^{*} \dagger$ & $0.97 \pm 0.06$ & $0.97 \pm 0.07^{*}$ & $0.94 \pm 0.06$ \\
\hline Average RPE & $13.73 \pm 2.98$ & $15.93 \pm 3.63^{\star}$ & $13.60 \pm 2.20$ & $16.80 \pm 2.65^{\star}$ \\
\hline EE (kcal/min) & $14.42 \pm 2.69+$ & $15.80 \pm 2.71^{*} \dagger$ & $9.05 \pm 2.17$ & $9.25 \pm 1.94^{\star}$ \\
\hline$\% \mathrm{VO}_{2}(\mathrm{ml} / \mathrm{kg} / \mathrm{min})$ & $37.83 \pm 4.49$ & $41.33 \pm 3.40^{*} \dagger$ & $34.50 \pm 5.79$ & $34.85 \pm 6.56^{*}$ \\
\hline
\end{tabular}

$\mathrm{HR}=$ Heart rate, RER $=$ Respiratory exchange ratio, RPE $=$ Rating of perceived exertion, EE $=$ Energy expenditure,

$\% \mathrm{VO}_{2}=$ Percentage of $\mathrm{VO}_{2}$ max during exercise

* Significant differences between modalities within sex, $\mathrm{p} \leq 0.05$

† Significant differences between sexes within modality, $p \leq 0.05$

The development of exercise prescriptions and programs is an individualized process which should consider differences among modalities, settings, and affective responses. Concern arises when using absolute recommendations for physical activity due to lack of adherence to the principle of individuality. In the present study, differences were seen between males and females for VO2max, running speed, VO2 during walking and running, and EE for walking and running in each setting. Of primary focus is the physiological and perceptual discrepancies between the track and treadmill when exercising at a self-selected pace. These differences merit further consideration.

Previous research explains the treadmill to be less physiologically stressing due to the lack of air resistance and muscular engagement to propel the body forward (Dasilva et al., 2011; Devi et al., 2014; Inoue et al., 2017). This research states the physiological cost of exercise on a treadmill appears to be reduced due to the leg swing phase of locomotion being strictly used to move the foot under the body to maintain an upright position (Devi et al., 2014). However, the results of the current study contradict those of previous research. Although speed was equivalent between the track and treadmill, HR was significantly elevated during treadmill exercise as compared to the track. Considering participants were familiar with exercise modalities, this potentially represents a greater physiological stress when exercising using this modality and could be confirmed by the significant increase in RPE during treadmill exercise as compared to the track. To replicate the demands of above-ground walking, previous research dictates the use of a $1 \%$ grade on the treadmill (Hall et al., 2012). It could be that the $1 \%$ grade coupled with the addition of a constant pace resulted in a larger muscular demand during the treadmill condition, eliciting an elevated HR and RPE, compared to above-ground walking where an individual can selfregulate pace based upon perceptual response. This difference may further be explained by individuals self-selecting a slower pace on the treadmill when compared to above-ground pace, such as the track. This may be the result of several factors such as a misconception of intensity, exercise anxiety or apprehension, or musculoskeletal limitations. Musculoskeletal limitations such as low quadriceps strength, hip flexion, and hip abduction have been seen to relate to lower selected walking pace (Hanson et al., 2011). However, if this slower pace were to be selected on the treadmill, it is evident that physiological parameters would not increase to the same extent as they would on the track. These results also show an interaction effect where males' EE was significantly greater on the treadmill as compared to the track. This could also be explained by the introduction of a $1 \%$ grade on the treadmill to replicate the muscular demands similar to those of 
the track exercise and the demand of maintaining the constant speed throughout the exercise duration.

The importance of considering the perceptual response to exercise conditions has garnered increased attention over the last decade given its critical role in adherence for long-term health benefits (Physical Activity Guidelines Advisory Committee, 2009). Participants in the current study perceived the track condition less physically strenuous than the treadmill regardless of pace. The results of the present study are in line with previous research examining the influence of autonomy in selection of exercise intensity in suggesting people will self-select an intensity within the ACSM's recommendations for developing and sustaining cardiorespiratory fitness (Ekkekakis \& Lind, 2006). In a study examining differences in physiological, affective, and perceptual responses at self-selected pace between track and treadmill settings, DaSilva and colleagues (2011) observed that treadmill walking was more physiological strenuous while perceived as more difficult and less positively affective. Likewise, the present study further corroborates findings which indicate that RPE at preferred and self-selected intensities can uncouple from normal metabolic indicators of exercise intensity (Devi et al., 2014). Limitations within the study did exist in that the researchers were unable to control the indoor environmental distractions. However, the indoor track was unavailable to outside users during testing sessions.

\section{PRACTICAL APPLICATIONS}

The present study observed a significantly lower RPE during the track condition, while RER was significantly elevated. Researchers have established increased enjoyment to influence perceived exertion regardless of intensity level (Gladwell et al., 2013), thus the influence of an individual's perception of effort or exertion on enjoyment may impact shortand long-term adherence to exercise prescriptions (Barnett et al., 2015). Differences in reduced perceived effort during trials indicate that individuals may choose to exercise on the track as opposed to the treadmill. This difference may partially be explained by the change in mechanics during the running phase while on a treadmill. The adjustments in gait may feel unnatural to individuals, thereby reducing their enjoyment compared to track running. In this study, both track and treadmill were indoors thus removing the potential environmental bias due to outdoor enjoyment, although moving along the track may have provided a changing scenery (Freitas et al., 2015).

By establishing the existing differences in physiological and perceptual responses to selfselected treadmill walking and running as compared to self-selected treadmill exercise, it is important for the strength and conditioning professional to further consider exercise modalities. Considering the task of producing the targeted adaptations is reliant on the appropriate exercise intensity, coaches should be aware of the difference in physiological response to prescribed running or walking on a treadmill as compared to a track. With the established difference in HR and RPE between the two modalities, exercise professionals (i.e. coaches) should consider proper adjustment to intensity when having an individual perform treadmill exercise based on measurements obtained from running or walking on a track. There may be potential benefits to exercise adherence with the utilization of track walking/running as compared to treadmill walking/running.

\section{ACKNOWLEDGEMENTS}

The researches wish to acknowledge all participants for their volunteered time and dedication to this study. No grant was received for the conduction of this study. No conflicts of interest are declared.

\section{REFERENCES}

1. American College of Sports Medicine. (2017). ACSM's guidelines for exercise testing and prescription. Lippincott Williams \& Wilkins

2. Amorim, P. R., Hills, A., \& Byrne, N. (2009, Jun). Treadmill adaptation and verification of self-selected walking speed: a protocol for children. Research Quarterly for Exercise and Sport, 80(2), 380-385. https://doi.org/10.1080/02701367.20 09.10599574

3. Antoniewicz, F., \& Brand, R. (2016). Dropping out or keeping up? Early-dropouts, late-dropouts, and maintainers differ in their automatic evaluations of exercise already before a 14-week exercise course. Frontiers in Psychology, 7, 838. https://doi.org/10.3389/fpsyg.2016.00838

4. Astorino, T. A., Robergs, R. A., Ghiasvand, F., Marks, D., \& Burns, S. (2000). Incidence of the oxygen plateau at VO2max during exercise testing to volitional fatigue. Journal of Exercise Physiology Online, 3(4), 1-12.

5. Barnett, A., Cerin, E., Vandelanotte, C., Matsumoto, A., \& Jenkins, D. (2015). Validity of treadmill- and track-based individual calibration methods for estimating free-living walking speed and VO2 using the Actigraph accelerometer. BMC Sports Science, Medicine \& Rehabilitation, 7, 29. https://doi.org/10.1186/s13102-015-0024-7

6. Brand, R., \& Ekkekakis, P. (2018). Affective-reflective theory of physical inactivity and exercise. German Journal 
of Exercise and Sport Research, 48(1), 48-58.

7. Browning, R. C., Baker, E. A., Herron, J. A., \& Kram, R. (2006, Feb). Effects of obesity and sex on the energetic cost and preferred speed of walking. Journal of Applied Physiology (1985), 100(2), 390-398. https://doi.org/10.1152/ japplphysiol.00767.2005

8. Ceci, R., \& Hassmen, P. (1991, Jun). Self-monitored exercise at three different RPE intensities in treadmill vs field running. Medicine \& Science in Sports \& Exercise, 23(6), 732-738. https://www.ncbi.nlm.nih.gov/pubmed/1886482

9. DaSilva, S. G., Guidetti, L., Buzzachera, C. F., Elsangedy, H. M., Colombo, H., Krinski, K., Dos Santos, S. L., De Campos, W., \& Baldari, C. (2009, Aug). The influence of adiposity on physiological, perceptual, and affective responses during walking at a self-selected pace. Perceptual Motor Skills, 109(1), 41-60. https://doi.org/10.2466/PMS.109.1.41-60

10. Dasilva, S. G., Guidetti, L., Buzzachera, C. F., Elsangedy, H. M., Krinski, K., De Campos, W., Goss, F. L., \& Baldari, C. (2011, Jun). Psychophysiological responses to selfpaced treadmill and overground exercise. Medicine \& Science in Sports \& Exercise, 43(6), 1114-1124. https://doi. org/10.1249/MSS.0b013e318205874c

11. Devi, R. K., Chakravarthy, K. M., \& Adinarayana, K. P. S. (2014). Comparative study of energy expenditure per unit time on track and treadmill during walking and running (1 mile). Journal of Evolution of Medical and Dental Sciences, 3(4), 798-807. https://doi.org/10.14260/jemds/2014/1905

12. Donnelly, J. E., Blair, S. N., Jakicic, J. M., Manore, M. M., Rankin, J. W., Smith, B. K., \& American College of Sports, M. (2009, Feb). American College of Sports Medicine Position Stand. Appropriate physical activity intervention strategies for weight loss and prevention of weight regain for adults. Medicine \& Science in Sports \& Exercise, 41(2), 459-471. https://doi.org/10.1249/MSS.0b013e3181949333

13. Ekkekakis, P., \& Lind, E. (2006, Apr). Exercise does not feel the same when you are overweight: the impact of selfselected and imposed intensity on affect and exertion. International Journal of Obesity, 30(4), 652-660. https://doi. org/10.1038/sj.ijo.0803052

14. Ekkekakis, P., Parfitt, G., \& Petruzzello, S. J. (2011, Aug 1). The pleasure and displeasure people feel when they exercise at different intensities: decennial update and progress towards a tripartite rationale for exercise intensity prescription. Sports Medicine, 41(8), 641-671. https://doi. org/10.2165/11590680-000000000-00000

15. Emerenziani, G. P., Migliaccio, S., Gallotta, M. C., Lenzi, A., Baldari, C., \& Guidetti, L. (2013). Physical exercise intensity prescription to improve health and fitness in overweight and obese subjects: a review of the literature. Health. Health, 5(06), 113-121

16. Freitas, L. A. G., Ferreira, S. d. S., Freitas, R. Q., Januário, R. S., Alves, R. C., Silva, A. C., Follador, L., Garcia, E. D., \& da Silva, S. G. (2015). Effect of self-selected and imposedintensity walking programs on fat oxidation in obese women. Journal of Exercise Physiology Online, 18(1), 62-70.

17. Gladwell, V. F., Brown, D. K., Wood, C., Sandercock, G. R., \& Barton, J. L. (2013, Jan 3). The great outdoors: how a green exercise environment can benefit all. Extreme Physiology \& Medicine, 2(1), 3. https://doi.org/10.1186/2046-7648-2-3

18. Hall, C., Figueroa, A., Fernhall, B., \& Kanaley, J. A. (2004, Dec). Energy expenditure of walking and running: comparison with prediction equations. Medicine \& Science in Sports \& Exercise, 36(12), 2128-2134. https://www.ncbi. nlm.nih.gov/pubmed/15570150

19. Hall, C. W., Holmstrup, M. E., Koloseus, J., Anderson, D., \& Kanaley, J. A. (2012). Do overweight and obese individuals select a "moderate intensity" workload when asked to do so? Journal of Obesity, 2012, 919051. https:// doi.org/10.1155/2012/919051

20. Hanson, N. J., Berg, K., Deka, P., Meendering, J. R., \& Ryan, C. (2011, Jun). Oxygen cost of running barefoot vs. running shod. International Journal of Sports Medicine, 32(6), 401-406. https://doi.org/10.1055/s-0030-1265203

21. Inoue, W., Ikezoe, T., Tsuboyama, T., Sato, I., Malinowska, K. B., Kawaguchi, T., Tabara, Y., Nakayama, T., Matsuda, F., \& Ichihashi, N. (2017, Apr). Are there different factors affecting walking speed and gait cycle variability between men and women in community-dwelling older adults? Aging Clinical and Experimental Research, 29(2), 215-221. https://doi.org/10.1007/s40520-016-0568-8

22. Levinger, I., Bronks, R., Cody, D. V., Linton, I., \& Davie, A. (2004, Nov). Perceived exertion as an exercise intensity indicator in chronic heart failure patients on Beta-blockers. Journal of Sports Science and Medicine, 3(YISI 1), 23-27. https://www.ncbi.nlm.nih.gov/pubmed/24778550

23. Loftin, M., Waddell, D. E., Robinson, J. H., \& Owens, S. G. (2010, Oct). Comparison of energy expenditure to walk or run a mile in adult normal weight and overweight men and women. Journal of Strength and Conditioning Research, 24(10), 2794-2798. https://doi.org/10.1519/ JSC.0b013e3181cc26cd

24. Manson, J. E., Greenland, P., LaCroix, A. Z., Stefanick, M. L., Mouton, C. P., Oberman, A., Perri, M. G., Sheps, D. S., Pettinger, M. B., \& Siscovick, D. S. (2002, Sep 5). Walking compared with vigorous exercise for the prevention of cardiovascular events in women. New England Journal of Medicine, 347(10), 716-725. https://doi.org/10.1056/ NEJMoa021067

25. Mooses, M., Mooses, K., Haile, D. W., Durussel, J., Kaasik, P., \& Pitsiladis, Y. P. (2015). Dissociation between running economy and running performance in elite Kenyan distance runners. Journal of Sports Science, 33(2), 136-144. https:// doi.org/10.1080/02640414.2014.926384

26. Morris, C. E., Owens, S. G., Waddell, D. E., Bass, M. A., Bentley, J. P., \& Loftin, M. (2014). Cross-validation of a recently published equation predicting energy expenditure to run or walk a mile in normal-weight and overweight adults. Measurement in Physical Education and Exercise Science, 18(1), 1-12.

27. Pfeiffer, K. A., Pivarnik, J. M., Womack, C. J., Reeves, M. J., \& Malina, R. M. (2002, Dec). Reliability and validity of the Borg and $\mathrm{OMNI}$ rating of perceived exertion scales in adolescent girls. Medicine \& Science in Sports \& Exercise, 34(12), 2057-2061. https://doi.org/10.1249/01. MSS.0000039302.54267.BF

28. Physical Activity Guidelines Advisory Committee. (2009, Feb). Physical Activity Guidelines Advisory Committee report, 2008. Nutrition Reviews, 67(2), 114-120. https://doi. org/10.1111/j.1753-4887.2008.00136.x

29. Pugh, L. G. (1970, May). Oxygen intake in track and treadmill running with observations on the effect of air resistance. The Journal of Physiology, 207(3), 823-835. https://www. ncbi.nlm.nih.gov/pubmed/5532903

30. Reuter, B., \& Dawes, J. (2016). Chapter 20: Program design and technique for aerobic endurance training. In Essentials of Strength Training and Conditioning: 4th Edition (pp. 567). Human Kinetics. 